\title{
Impacts of climate change and agricultural activities on water quality in the Lower Kaidu River Basin, China
}

\author{
BA Wulong ${ }^{1,2}$, 'DU Pengfei ${ }^{1}$, LIU Tie ${ }^{2}$, BAO Anming ${ }^{2}$, CHEN Xi², LIU Jiao ${ }^{3}$, \\ QIN Chengxin ${ }^{1}$
}

1. State Key Laboratory of Environmental Simulation and Pollution Control, School of Environment, Tsinghua University, Beijing 100084, China;

2. State Key Laboratory of Desert and Oasis Ecology, Xinjiang Institute of Ecology and Geography, CAS, Urumqi 830011, China;

3. School of Energy and Power Engineering, Xihua University, Chengdu 610039, China

\begin{abstract}
In the context of climate change and over-exploitation of water resources, water shortage and water pollution in arid regions have become major constraints to local sustainable development. In this study, we established a Soil and Water Assessment Tool (SWAT) model for simulating non-point source (NPS) pollution in the irrigation area of the lower reaches of the Kaidu River Basin, based on spatial and attribute data (2010-2014). Four climate change scenarios (2040-2044) and two agricultural management scenarios were input into the SWAT model to quantify the effects of climate change and agricultural management on solvents and solutes of pollutants in the study area. The simulation results show that compared to the reference period (2010-2014), with a decline in streamflow from the Kaidu River, the average annual irrigation water consumption is expected to decrease by $3.84 \times 10^{8} \mathrm{~m}^{3}$ or $8.87 \%$ during the period of $2040-2044$. Meanwhile, the average annual total nitrogen (TN) and total phosphorus (TP) in agricultural drainage canals will also increase by $10.50 \%$ and $30.06 \%$, respectively. Through the implementation of agricultural management measures, the TN and TP in farmland drainage can be reduced by $14.49 \%$ and $16.03 \%$, respectively, reaching $661.56 \mathrm{t}$ and $12.99 \mathrm{t}$, accordingly, and the increasing water efficiency can save irrigation water consumption by $4.41 \times 10^{8} \mathrm{~m}^{3}$ or $4.77 \%$. The results indicate that although the water environment in the irrigation area in the lower reaches of the Kaidu River Basin is deteriorating, the situation can be improved by implementing appropriate agricultural production methods. The quantitative analysis results of NPS pollutants in the irrigation area under different scenarios provide a scientific basis for water environmental management in the Kaidu River Basin.
\end{abstract}

Keywords: climate change; agricultural management; non-point pollutants; SWAT; Kaidu River Basin; water quality

Received: 2018-07-02 Accepted: 2018-12-27

Foundation: National Key Research and Development Program of China, No.2017YFC0404501; Tianshan Innovation Team Project of the Xinjiang Department of Science and Technology, No.Y744261

Author: Ba Wulong (1984-), PhD, specialized in climate change and hydrological response research. E-mail: bawulong@sina.com

*Corresponding author: Du Pengfei (1970-), PhD and Professor, E-mail: dupf@tsinghua.edu.cn 


\section{Introduction}

The arid region of northwest China is located in the hinterland of Euroasian continent where the geographic conditions are can be characterized by inland river basins and alpine forests. The regions experience high levels of precipitation and water vapor due to the high mountains, and the mountains provide water resources for the downstream oases (Chen, 2002). In the context of climate change, water resource systems from ice and snow melt are becoming more and more vulnerable, resulting in an uncertain water supply (Chen et al., 2012; Yu et al., 2019). Additionally, human activities in the middle and lower reaches of the inland river basins have caused pollution of the water environment (Wang, 1999). Disruptions to the water systems are highly problematic, as the dry climate and spatial and temporal uneven distribution of water make the resource a limiting factor for oases agricultural activities (Chen et al., 2010). Both the shortage of water resources and the low self-purification capacity of inland rivers make the water environmental management in the region a greater challenge. Under a given level of pollutant emissions, reductions in water resources have exacerbated the deterioration of water quality and eco-environment. Therefore, analyzing the trends of water resources and non-point source (NPS) pollution in the arid river basins by comprehensively considering climate change and human activities is of practical significance for managing water resources and improving the eco-environment around the basins.

Due to the complexity of the water environment, current research has mainly focused on the individual effects of climate change or human activities on water resources (Chamchati and Bahir, 2011), and there have been relatively few studies on the combined impact of these two factors on both water resources and water quality. The distributed hydrological models based on physical processes can quantify NPS pollutants in the river basins and are an effective approach to study a specific water environment (Akhavan et al., 2010). Among them, the Soil and Water Assessment Tools (SWAT) model is a widely used approach due to its powerful function and open program code (Al-Mukhtar et al., 2014; Dechmi and Skhiri, 2013; Moriasi et al., 2013; Zhang and Zhang, 2011). With the continuous improvement in the performance of the model, the use of SWAT has expanded from the basin scale to the irrigation district (Xie and Cui, 2011). Unlike the black box model, SWAT model can directly simulate the migration and conversion of water, sand, and nutrients. The physical properties of SWAT allow users to freely change the input conditions to simulate climatic conditions, human activities, and management measures under different scenarios (Griensven et al., 2012). At present, in the study of future water environment, the use of possible changes in forecasted climate assumptions can lead to an incorrect representation of actual conditions of climate change. Some studies have used Global Climate Model (GCM) output data to predict climate change, but it is difficult to accurately capture regional climate change signals using GCM, and using this method reduce the credibility of hydrological process simulations (Dibike and Coulibaly, 2005).

The Kaidu River is a typical inland river originated from the Sarming Mountain of the Tianshan Mountains in Xinjiang, northwest China. Bosten Lake, at the tail of the Kaidu River, is the largest interior freshwater lake in China. In the past 50 years, four counties around the lake have diverted water from the Kaidu River to develop agriculture and indus- 
try (Lei et al., 2015; Shen et al., 2017; Xiao et al., 2015). Extensive agricultural irrigation and industry consumed a large amount of freshwater from the lake. In addition, the amount of industrial sewage continued to increase. For these reasons, the water quality of Bosten Lake has become salter (Guo et al., 2015). It is widely accepted that in the arid and semi-arid regions with fragile eco-environments, once the water environment is deteriorated, it will be difficult to reverse. Existing research on the downstream irrigation area of the Kaidu River Basin has mainly focused on ecowater requirements and/or water and salt cycling issues (Liu et al., 2015; Mostofa et al., 2017; Rusuli et al., 2015; Wang et al., 2014; Zuo et al., 2007). However, it has not yet established a systematic analysis of the combined impacts of climate change and human activities on the generation and migration of NPS pollutants in this region.

Given the lack of a systematic analysis, we used the SWAT model to simulate the NPS pollution of the irrigation area in the lower reaches of the Kaidu River Basin. First, we calibrated and validated the SWAT model and simulated the distributions of nitrogen and phosphorus pollutants in the study area. Second, we identified the water environmental pollution, and finally, we separately predicted the NPS pollution load of inlet water of the Kaidu River and farmland sewage by using four climate change scenarios and two management measure scenarios. The simulations and predictions of NPS pollution can provide technical support for water environmental protection and treatment in the lower reaches of the Kaidu River.

\section{Materials and methods}

\subsection{Study area}

The Kaidu River Basin is located in Xinjiang Uygur Autonomous Region, China and lies in the southern Tianshan Mountains covering an area of 43,890 $\mathrm{km}^{2}$ (Figure 1). The Kaidu River originates from the Sarming Mountain, flows through the Yulduz and Yanqi Basins, and eventually enters into the Bosten Lake. The terrain of the Kaidu River Basin is tilted from northwest to southeast. The Kaidu River has a total length of $560 \mathrm{~km}$, which is the largest River in Bayingolin Mongolian Autonomous Prefecture, Xinjiang, China. It
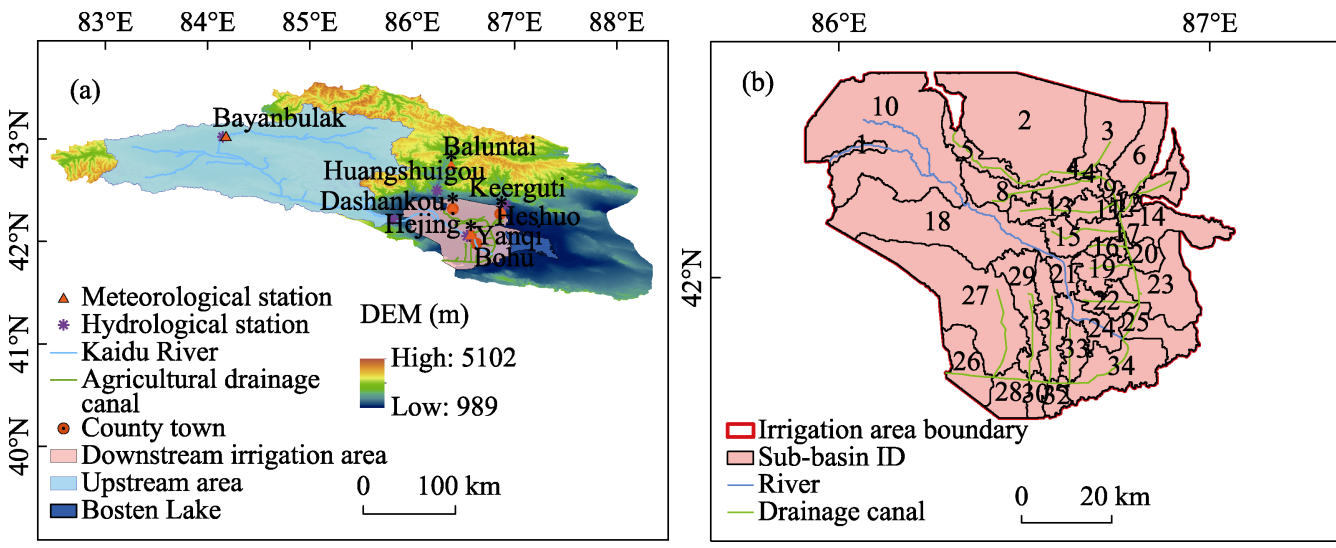

Figure 1 Locations of the Kaidu River Basin (a) and irrigation area of the lower reaches of the Kaidu River Basin (b) 
contributes to $35.1 \times 10^{8} \mathrm{~m}^{3}$ in the annual runoff volume, accounting for $85 \%$ of the annual inflow into the Bosten Lake (Wang et al., 2018). In addition to the Kaidu River, the Huangshui River, Qingshui River and 27 agricultural drainage canals flow into the Bosten Lake. In 2010, the area of agricultural land in the Kaidu River Basin reached $2539 \mathrm{~km}^{2}$. There are five meteorological stations (Bayanbulak, Baluntai, Hejing, Heshuo, and Yanqi) and five hydrological stations (Bayanbulak, Dashankou, Yanqi, Huangshuigou and Keerguti) in the Kaidu River Basin (Basher et al., 2010, Liu et al., 2011).

\subsection{Model and input data}

Establishing a hydrological model is the most effective way to quantitatively simulate the NPS pollution. The SWAT model was developed by the US Department of Agriculture to simulate the transportation of runoff, sediment, and nutrients in ungauged watersheds, and has also been widely used for NPS pollution calculations at different scales (Bouraoui and Grizzetti, 2014; Kaini and Nicklow, 2012; Pongpetch et al., 2015). The SWAT model can formulate different irrigation and fertilization measures based on the growth characteristics of crops in the study area and simulate the loss of nutrients in surface runoff from farmland under different management systems. Operating the SWAT model requires a large amount of spatial and property data. The details of the input data were described in Neitsch et al. (2011).

The digital elevation model (DEM) data with a resolution of $90 \mathrm{~m}$ was obtained by Shuttle Radar Topography Mission (SRTM). Land use data at a scale of 1:100,000 were provided by the Xinjiang Institute of Ecology and Geography, Chinese Academy of Sciences (CAS). Soil map data at a scale of 1:1,000,000 were provided by the Harmonized World Soil Database (HWSD). Daily meteorological data from 2009 to 2014 at Bayanbulak, Baluntai and Yanqi meteorological stations were downloaded from the China Meteorological Science Data Sharing Service (http://cdc.cma.gov.cn/home.do). Daily runoff data from 2009 to 2014 for Dashankou, Yanqi, Huangshuigou, and Keerguti hydrological stations were obtained from the Xinjiang Hydrographic Bureau. Monthly water-quality monitoring data for 2009 through 2014 for the Yanqi hydrological station were provided by the Environmental Monitoring Station of Bayingolin, Xinjiang.

The water quality monitoring parameters used in this study were total nitrogen (TN) and total phosphorus (TP). The analytical methods for TN and TP were potassium persulfate oxidative ultraviolet spectrophotometry and ammonium molybdate spectrophotometry, respectively. Fertilization data for 2010 through 2014 were obtained from the Bayingolin Statistical Yearbook.

After constructing a basic database of the hydrological model, the SWAT completed a spatial dispersion of the basin by dividing it into several sub-basins. The river network and drainage canals were embedded in the SWAT model. We identified and generalized 25 major drainage canals in the study area, and outlined 15 vectorized agricultural drainage canals. Based on the overlay analysis of land use maps, soil type maps and slope maps, we divided the irrigation area in the lower reaches of the Kaidu River Basin into 34 sub-basins (Figure 1) and 550 hydrological response units (HRUs) using the SWAT model. 


\subsection{Climate change and management scenarios}

The irrigation area in the lower reaches of the Kaidu River Basin is characterized by an arid climate, with the average annual precipitation of about $60 \mathrm{~mm}$ and the average annual evaporation of more than $2000 \mathrm{~mm}$ (Wang et al., 2011). In the study area, precipitation cannot form surface runoff on the plains. Drought climate characteristics make the Kaidu River runoff and water environment extremely sensitive to climate change (Wang et al., 2018). Therefore, we analyzed potential future changes in the water environment of the Kaidu River by adding scenarios that may occur in a future climate and by adding management scenarios to investigate whether management measures can potentially improve the water environment.

In our previous study, we used the climate modeling outputs of three dynamic downscaling models (i.e., HadGEM3-RA, RegCM4, and SUN-MM5) and a set of statistical downscaling models under two greenhouse gas emission scenarios to simulate the future precipitation change and streamflow of the Kaidu River Basin (Ba et al., 2018). The climate change signals between the reference period (i.e., 2010-2014) and the future period (i.e., 2040-2044) were extracted for the scenario analysis. According to the simulations, under the two greenhouse gas emission scenarios (i.e., RCP 4.5/8.5), the four model downscaling results simulated a temperature increase of $0.5-1.9^{\circ} \mathrm{C}$ in the Kaidu River Basin, with a precipitation change of $-10 \%$ to $30 \%$ and a corresponding streamflow change between $-20 \%$ and $10 \%$. Simulation results showed that the precipitation and streamflow in the Kaidu River Basin will increase as temperatures rise, but a large increase in evaporation will lead to a reduction in streamflow as temperatures rise to a certain degree. In order to analyze the impact of irrigation management methods on water quality and to understand the relationship between the streamflow and water quality in the future climate change scenarios, we set up four future climate change scenarios in the lower reaches of the Kaidu River Basin based on changes in precipitation, temperature and streamflow (Table 1). In addition, by considering the impacts of human activities, we added two scenarios focused on management measures to deal with reductions in water supply and increases in water pollution.

Table 1 Climate change (2040-2044) and agricultural management measure scenarios used in this study

\begin{tabular}{cccc}
\hline Climate scenarios & Temperature change $\left({ }^{\circ} \mathrm{C}\right)$ & Precipitation change (\%) & Streamflow change (\%) \\
\hline A & +0.5 & -10 & -10 \\
B & +0.7 & +10 & +10 \\
C & +1.3 & +20 & -10 \\
D & +1.9 & +30 & -20 \\
\hline Management scenarios & \multicolumn{3}{c}{ Measures } \\
\hline E & Agricultural irrigation efficiency increased from $58 \%$ to $75 \%$ \\
F & Amount of fertilizer application reduced by $20 \%$ \\
\hline
\end{tabular}

It has been previously studied that at the farm level, replacing furrows with drip irrigation can increase water use efficiency by $50 \%-90 \%$ (Alcon et al., 2011). In this study, we used the median and adjusted the irrigation coefficient of the SWAT model from $58 \%$ to $75 \%$. According to the field survey, the proportion of nitrogen and phosphorus fertilizer in the 
study area is higher than the national level. Therefore, we reduced the current dosage by $20 \%$ to improve the structure of fertilizer application. We assumed that the other input conditions under each scenario setting were unchanged when simulating the change trend of pollution load in the study area.

\subsection{Evaluation criteria}

In order to accurately simulate the hydrological processes and NPS pollution of the irrigation area in the lower reaches of the Kaidu River Basin, we calibrated and validated the SWAT model firstly using monthly flow data from 2011 through 2014. Moreover, the water quality simulation parameters were calibrated using water quality monitoring data during 2009-2014 at the Yanqi hydrological station.

In this study, the performance of the SWAT model was evaluated on the basis of the Nash efficiency coefficient (NSE) (Moriasi et al., 2007), the certainty coefficient $\left(R^{2}\right)$ (Mihon et al., 2013), and the percent bias (PBIAS) (Gupta et al., 1999). Model performance was evaluated as "satisfactory" if $R^{2}>0.6,0.50<\mathrm{NSE} \leqslant 0.65$, and $\pm 30 \leqslant \mathrm{PBIAS}< \pm 55$.

\section{Results}

\subsection{Model calibration}

A Sequential Uncertainty Fitting ver.2 (SUFI-2) method was used for parameter sensitivity analysis of the SWAT model (Abbaspour et al., 2004). The sensitivity analysis includes 27 parameters that have an important impact on streamflow and water quality calculations. Key parameters were determined after 2,000 automatic calibrations and three iterations, and the most sensitive 10 parameters were chosen. The initial and fitted values of parameters are shown in Table 2.

The observed and simulated time series of streamflow are shown in Figure 2. Scatter plots of the simulated streamflow and TN and TP are shown in Figures 3 and 4, respectively. For ease of expression, we enlarged the value of TP 100 times and put the fitting curves of TN and TP into a single figure (Figure 4). Performance indices for the calibration and validation periods are listed in Table 3. In the calibration and validation periods, the NSE varied from

Table 2 Parameters used for calibration of the SWAT model (2012-2013)

\begin{tabular}{clcc}
\hline Parameter & \multicolumn{1}{c}{ Definition } & Ranges & Fitted value \\
\hline LAT_TTIME & Lateral flow travel time & $0.00-180.00$ & 62.00 \\
NPERCO & Nitrogen percolation coefficient & $0.00-1.00$ & 0.21 \\
ALPHA_BF & Baseflow alpha factor & $0.00-1.00$ & 0.25 \\
GW_REVAP & Groundwater evaporation coefficient & $0.02-0.20$ & 0.02 \\
GW_DELAY & Groundwater delay & $0.00-500.00$ & 14.00 \\
ESCO & Soil evaporation compensation factor & $0.00-1.00$ & 0.19 \\
BIOMIX & Biological mixing efficiency & $0.00-1.00$ & 0.26 \\
USLE_P & USLE equation support practice & $0.00-1.00$ & 0.26 \\
BC1 & Rate constant for biological oxidation of $\mathrm{NH}_{3}$ & $0.10-1.00$ & 0.55 \\
BC2 & Rate constant for biological oxidation $\mathrm{NO}_{2}$ to $\mathrm{NO}_{3}$ & $0.20-2.00$ & 1.10 \\
\hline
\end{tabular}


Table 3 Calibration and validation results of model parameters

\begin{tabular}{clllc}
\hline Variable & \multicolumn{1}{c}{ Period } & $R^{2}$ & NSE & PBIAS (\%) \\
\hline \multirow{2}{*}{ Streamflow } & Calibration (2012/01-2013/12) & 0.84 & 0.80 & -28.57 \\
& Validation (2014/01-2014/12) & 0.86 & 0.83 & 7.46 \\
\multirow{2}{*}{ TN (t) } & Calibration (2012/01-2013/12) & 0.85 & 0.79 & -27.32 \\
& Validation (2014/01-2014/12) & 0.86 & 0.82 & 10.68 \\
TP (t) & Calibration (2012/01-2013/12) & 0.79 & 0.75 & -35.34 \\
& Validation (2014/01-2014/12) & 0.81 & 0.73 & 12.35 \\
\hline
\end{tabular}

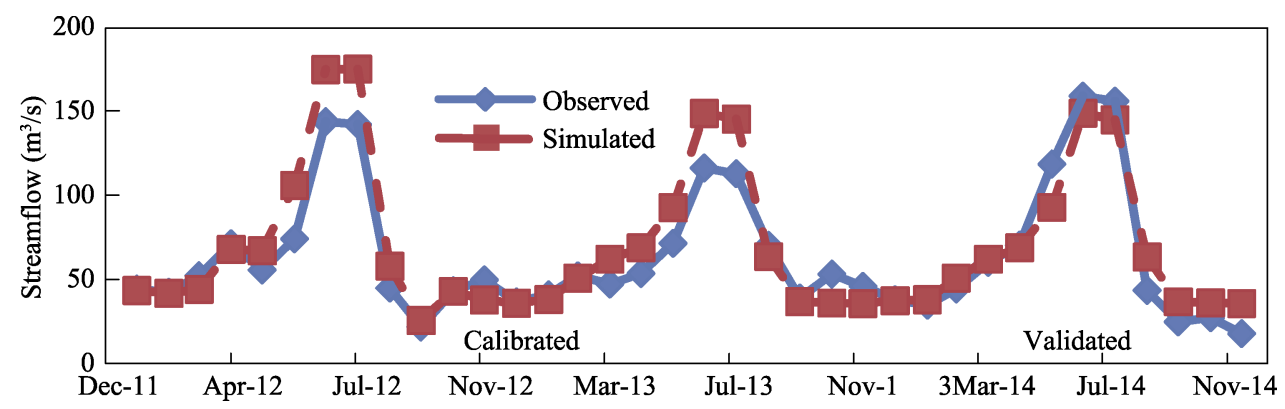

Figure 2 Calibration and validation of monthly streamflow at the Yanqi hydrological station (2012-2014)
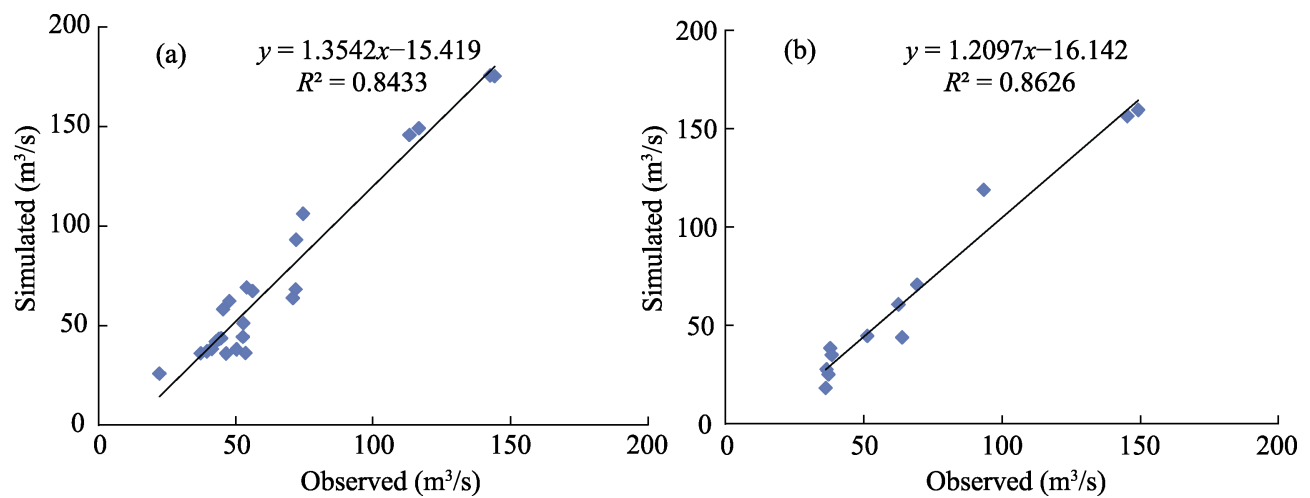

Figure 3 Simulated and observed values of streamflow in the calibration (a) and validation periods (b) (2012-2014)
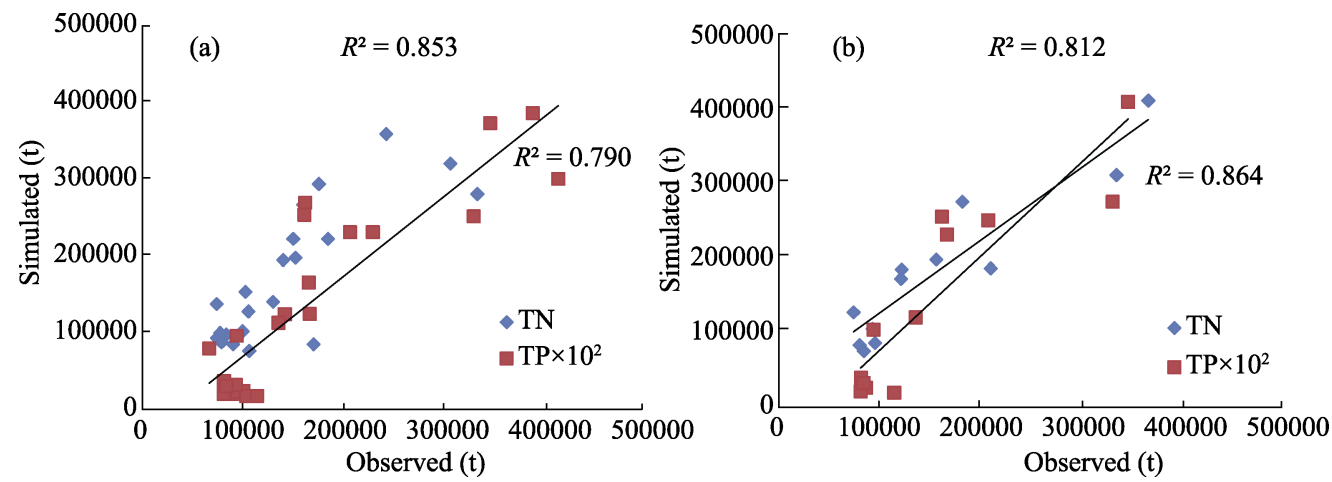

Figure 4 Simulated and observed values of TN and TP in the calibration (a) and validation periods (b) (2012-2014) 
0.83 for streamflow to 0.73 for TP, the $R^{2}$ values varied from 0.86 for streamflow and TN to 0.79 for TP, and the PBIAS varied from $7.46 \%$ for streamflow to $-35.34 \%$ for TP. These data indicated that the simulation results of streamflow were better than those of TN and TP. Overall, the NSE of all variables was higher than 0.6, which suggests that the SWAT model can capture the major hydrological processes of the irrigation area in the lower reaches of the Kaidu River Basin and that the results of model parameters are satisfactory.

\subsection{Distribution of NPS pollutant load in Lower Kaidu River Basin}

In this study, the SWAT model was used to simulate typical pollution loads such as nitrogen and phosphorus of the irrigation area of the lower reaches of the Kaidu River Basin. Specifically, the spatial distribution of annual average NPS pollution loads in the study area during 2010-2014 was analyzed, and the spatial distribution of nitrogen and phosphorus loads was plotted (Figure 5). The amount of nutrient loss in the study area exhibited a large spatial heterogeneity and the pollution of TN was larger than that of TP. In the upper reaches of the irrigation area, the cultivated land area was small and the population was low, thus, the NPS pollution load was relatively low. The area with an annual average TN load below $0.04 \mathrm{t} / \mathrm{km}^{2}$ is located near the Shangyou Town, while the area with an annual average TP load below $0.01 \mathrm{t} / \mathrm{km}^{2}$ is mainly concentrated in the 24th Regiment of the Second Division of the Xinjiang Production and Construction Corps. The risk of agricultural NPS pollution in these regions is relatively low. In the irrigated regions around the Bosten Lake, the three drainage canals of the 22nd Regiment, Shengli, and Dongfeng had a higher TN and TP loads. The annual average TN and TP pollution loads in these regions exceeded $0.20 \mathrm{t} / \mathrm{km}^{2}$ and $0.01 \mathrm{t} / \mathrm{km}^{2}$, respectively. The data indicated that these regions are at a high risk of agricultural NPS pollution. Our data show that the reason for the high NPS pollution around the lake in the irrigation area is the topographic factor. The Yanqi Basin, where the study area is located, is mainly surrounded by mountains and the central part is the flood plain. The sur
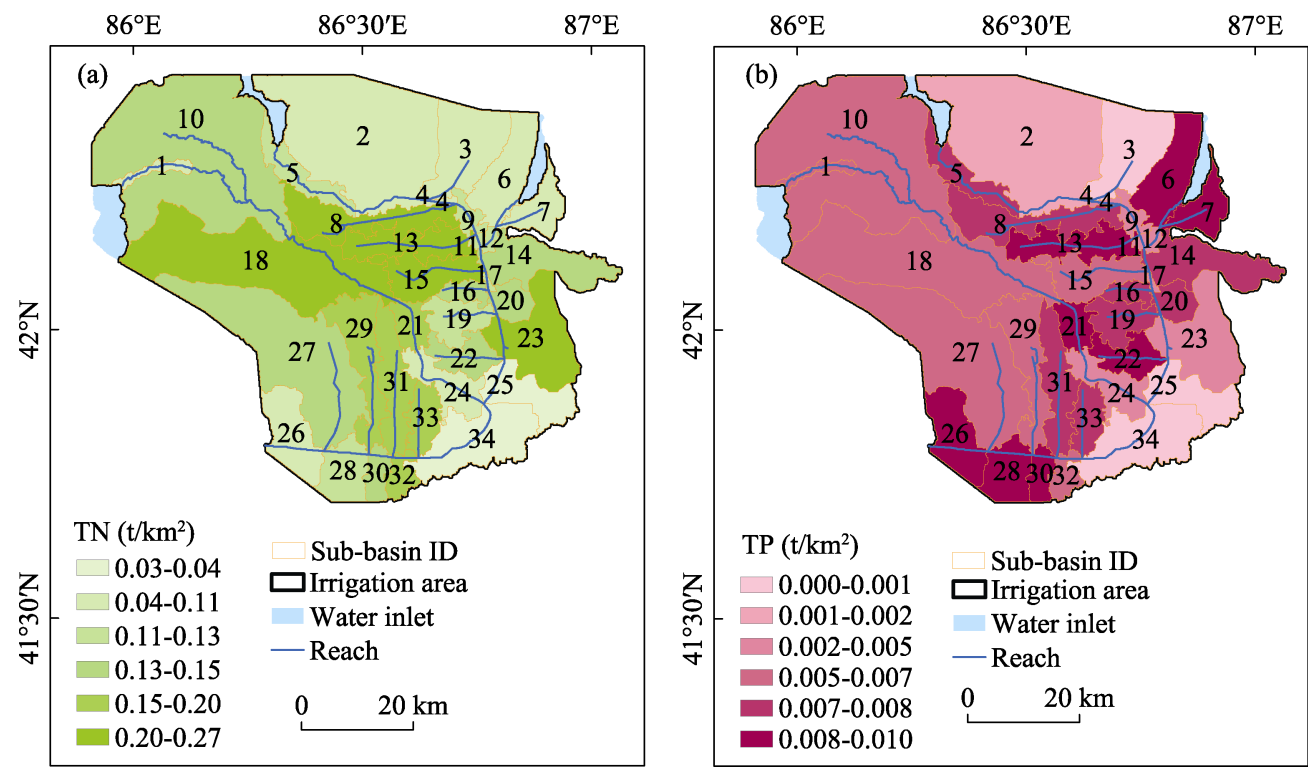

Figure 5 Distributions of annual average total nitrogen (TN) (a) and total phosphorus (TP) (b) (2010-2014) 
face water permeability of the exit area of the Kaidu River Valley is good, almost no salinization and NPS pollution occur. However, the region is easily blocked by the weakly permeable soil layer in the low-lying area, where the soil is prone to salinization and NPS contaminants are easily accumulated.

\subsection{Contributions of all sub-basins to NPS pollution in Lower Kaidu River Basin}

Table 4 lists the streamflow and TN and TP for Kaidu River and 14 generalized drainage areas for the period of 2010 through 2014. The results show that Kaidu River is a major contributor to water supply and nitrogen and phosphorus pollution in the Bosten Lake, with water supply accounting for $84.29 \%$ of the average annual water of the lake, and $75.19 \%$ of TN and $38.02 \%$ of TP flow into the lake. Agriculture is the major source of NPS pollutants into the lake. The TN and TP entering the Bosten Lake through the drainage canals could reach up to $24.81 \%$ and $61.98 \%$ of the total input, reaching $773.74 \mathrm{t}$ and $15.49 \mathrm{t}$ respectively. According to the location where the drainage canal discharges into the Bosten Lake, we divided the 14 generalized drainage canals into three groups, including the Big Lake District, Yellow Water District, and the Small Lake District (Figure 6).

The TN and TP discharged into the Yellow Water District accounted for $80.97 \%$ and $48.87 \%$ of the total pollutants in agricultural sewage, respectively. These data indicated that the Yellow Water District is the region most affected by NPS pollution in Bosten Lake. The TN and TP pollutants discharged into the Small Lake District were larger than those discharged into the Big Lake District, which accounted for $15.13 \%$ and $37.31 \%$ of the total pollution load, respectively.

Table 4 Average annual non-point source (NPS) pollutant emissions and streamflow discharge for each drainage canal (2010-2014)

\begin{tabular}{|c|c|c|c|c|c|}
\hline Sub-basin ID & Receiving water & Drainage canal & $\mathrm{TN}(\mathrm{t})$ & $\mathrm{TP}(\mathrm{t})$ & Discharge $\left(10^{4} \mathrm{~m}^{3} / \mathrm{s}\right)$ \\
\hline 24 & \multirow{5}{*}{$\begin{array}{c}\text { Big } \\
\text { Lake } \\
\text { District }\end{array}$} & Kaidu River & 2345.36 & 9.50 & 225896.46 \\
\hline 16 & & Halayin, Dongdahan & 4.16 & 0.24 & 723.98 \\
\hline 19 & & Benbutu, 25th Regiment & 9.52 & 0.60 & 1539.51 \\
\hline 22 & & Bohu Town, Wulan Town & 10.29 & 0.64 & 1485.38 \\
\hline 7 & & Bortu, 26th Regiment West & 6.26 & 0.66 & 1545.33 \\
\hline 2 & \multirow{6}{*}{$\begin{array}{l}\text { Yellow } \\
\text { Water } \\
\text { District }\end{array}$} & Huangshui River & 499.58 & 2.70 & 12633.36 \\
\hline 8 & & $\begin{array}{l}\text { 22nd Regiment North and } \\
\text { South }\end{array}$ & 36.69 & 1.21 & 2624.37 \\
\hline 13 & & Shengli, Beigan & 26.85 & 0.99 & 2331.01 \\
\hline 15 & & Dongfeng & 24.11 & 0.81 & 1685.94 \\
\hline 3 & & $\begin{array}{l}\text { 6th and 4th Companies of } \\
\text { the } 24 \text { th Regiment }\end{array}$ & 16.6 & 0.01 & 101.94 \\
\hline 6 & & Qingshui River West and East & 22.64 & 1.85 & 1516.93 \\
\hline 27 & \multirow{4}{*}{$\begin{array}{c}\text { Small } \\
\text { Lake } \\
\text { District }\end{array}$} & Tuanjie & 61.52 & 3.28 & 10091.55 \\
\hline 29 & & Jiefang, 40 Lichengzi & 22.58 & 1.03 & 2461.36 \\
\hline 31 & & 27th Regiment, Yongning Town & 23.03 & 0.96 & 2091.49 \\
\hline 33 & & Yongning Town East, Chaganur & 9.91 & 0.51 & 1268.55 \\
\hline \multicolumn{3}{|c|}{ Total } & 3119.10 & 24.99 & 267997.16 \\
\hline
\end{tabular}




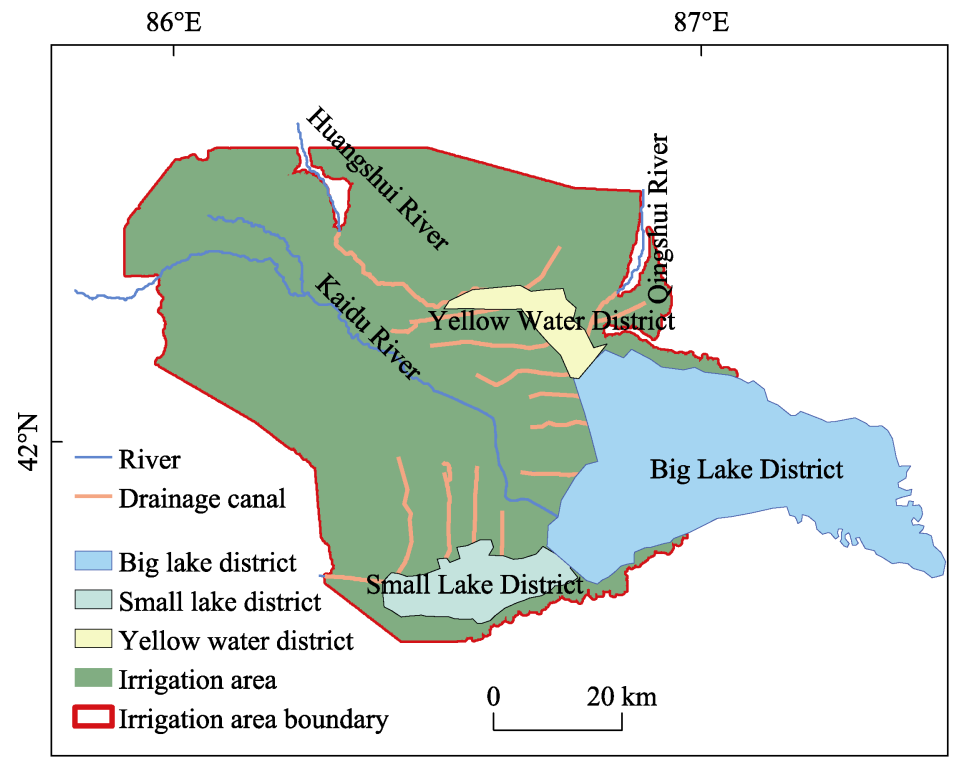

Figure 6 Drainage map of Kaidu River irrigation area

\subsection{Response of NPS pollution under different scenarios}

By inputting six scenarios related to climate change and agricultural management measures into the SWAT model, we obtained response results of the streamflow and NPS pollutants of the Kaidu River and drainage canals under different scenarios. The amount of agricultural sewage is closely related to the change of streamflow to the Kaidu River (Table 5). With a reduction of water supply to the Kaidu River, the amount of water available for agriculture is even more strained. However, the load of NPS pollutants increases with the reduction of agricultural water use. For example, the average annual irrigation water consumption under

Table 5 Changes of NPS pollution in the Kaidu River and drainage canals under different scenarios

\begin{tabular}{cccccc}
\hline Scenarios & Water source & Precipitation $(\mathrm{mm})$ & Discharge $\left(\mathrm{m}^{3} / \mathrm{s}\right)$ & $\mathrm{TN}(\mathrm{t})$ & $\mathrm{TP}(\mathrm{t})$ \\
\hline \multirow{2}{*}{ Reference period } & Drainage & 79.51 & $4.21 \times 10^{8}$ & 773.73 & 15.47 \\
& River & 246.47 & $2.26 \times 10^{9}$ & 2345.36 & 9.50 \\
\multirow{2}{*}{ Scenario A } & Drainage & 71.56 & $4.03 \times 10^{8}$ & 704.39 & 13.60 \\
& River & 221.82 & $1.93 \times 10^{9}$ & 2233.16 & 9.12 \\
Scenario B & Drainage & 87.46 & $4.37 \times 10^{8}$ & 845.33 & 21.88 \\
& River & 271.12 & $2.58 \times 10^{9}$ & 2485.97 & 15.21 \\
Scenario C & Drainage & 95.41 & $4.09 \times 10^{8}$ & 847.70 & 20.98 \\
& River & 295.76 & $1.94 \times 10^{9}$ & 2331.32 & 13.70 \\
Scenario D & Drainage & 103.36 & $3.84 \times 10^{8}$ & 854.98 & 20.20 \\
& River & 320.41 & $1.61 \times 10^{9}$ & 2222.45 & 12.87 \\
Scenario E & Drainage & 79.51 & $4.41 \times 10^{8}$ & 773.73 & 15.47 \\
& River & 246.47 & $2.26 \times 10^{9}$ & 2345.36 & 9.50 \\
Scenario F & Drainage & 79.51 & $4.21 \times 10^{8}$ & 661.56 & 12.99 \\
& River & 246.47 & $2.26 \times 10^{9}$ & 2312.59 & 8.93 \\
\hline
\end{tabular}


Scenario D will decrease by $3.84 \times 10^{8} \mathrm{~m}^{3}$ or $8.87 \%$ compared with the reference period (2010-2014), while the average annual TN and TP in agricultural drainage will increase by $10.50 \%$ and $30.06 \%$, respectively. The results indicate that the loss of NPS pollutants is closely related to the change trend of precipitation. Simulation results of the four climate change scenarios show that, although precipitation is relatively low in the study area, the loss of agricultural NPS pollutants is also accompanied by precipitation and streamflow processes. The result of Scenario E shows that, after increasing the efficiency of water use, the discharge from farmland drainage canals is increased by $4.41 \times 10^{8} \mathrm{~m}^{3}$ or $4.77 \%$ over the reference period, while the amount of NPS pollutants does not change. After a $20 \%$ reduction in fertilizer application, the flow in the farm drainage canal does not change, the TN and TP are reduced by $14.49 \%$ and $16.03 \%$, reaching $661.56 \mathrm{t}$ and $12.99 \mathrm{t}$ respectively.

\section{Discussion}

Although this study does not calibrate the variables of components TN and TP in the water quality parameters, the SWAT model simulates the trends of TN and TP under different climate change and agricultural management scenarios, and the simulation results can be used as a reference. The trends of TN and TP under different climate change scenarios indicate that, due to the use of chemical fertilizers and pesticides in the irrigation area in the lower reaches of the Kaidu River Basin, the contents of nitrate-nitrogen, organic nitrogen and mineral phosphorus in the surface soil are higher than those of other soil layers. This makes the contaminants susceptible to precipitation. In addition, the interception of nutrients by the roots of arable land is relatively weak, and soil erosion is more likely to occur, resulting in the loss of nitrogen and phosphorus. By reducing the fertilizer application by $20 \%$, we found that the TN and TP in agricultural drainage canals were significantly reduced, and the largest reduction components were nitrate-nitrogen and mineral phosphorus, with the contributions of $16.55 \%$ and $16.36 \%$, respectively.

In the past 70 years, the amount of agricultural water diversion on both sides of the Kaidu River has increased each year, decreasing both the amount of water entering Bosten Lake and the water level of the lake. Due to the decline in freshwater entering the lake and the increase of farmland drainage into the lake, the salinity of the lake has increased and the water quality in some areas has reached eutrophication. The simulation results under the climate change scenarios indicate that the water environment of the Kaidu River Basin will face more severe challenges, but that by implementing a reasonable strategy for managing industrial and agricultural wastewater, the situation can be improved.

The lack of daily water quantity and quality data in the agricultural drainage did limit this study somewhat. However, the SWAT model performs well in streamflow simulations. In addition, we only considered climate change in our future scenarios. We did not consider the impact of land use changes on NPS pollution. Different land use types contribute differently to non-point source pollution loads, thus, we recommend follow-up studies take into account a scenario in which land use changes.

\section{Conclusions}

This study used the SWAT model to analyze the NPS pollution in a typical arid basin. The spatial distribution of NPS pollution in the Yanqi Basin was obtained. Considering changes 
in water supply and precipitation intensity under several different future climate change conditions, the contribution of NPS pollutants to the Kaidu River and drainage canals was calculated and different future scenarios developed. Our primary findings were as follows:

(1) The loss of nitrogen and phosphorus nutrients in the study area had a certain degree of spatial heterogeneity. The nitrogen and phosphorus loads in the irrigation areas around the lake were relatively high, as they were affected by topographic factors and were in a high-risk area for agricultural NPS pollution.

(2) From 2010 through 2014, the average annual amount of TN and TP entering the Bosten Lake through the drainage canal accounted for $24.81 \%$ and $61.98 \%$ of the total lake input, reaching $773.74 \mathrm{t}$ and $15.49 \mathrm{t}$ respectively. This indicates that NPS pollution in agriculture is an important source of pollutants entering the lake.

(3) There are significant differences in the trends of changes in TN and TP in the Kaidu River and drainage canals under different climate scenarios. In the future, the water supply in the Kaidu River may decrease, while the nutrient load in the drainage canals could increase. This may lead to a deterioration of water quality of the Bosten Lake in the future, and the management of water environment could face severe challenges.

(4) Simulation results of management measures showed that after improving the water use efficiency, the streamflow of drainage canals will be increased by $4.77 \%$. The TN and TP in the drainage canals will decrease after the fertilizer application is reduced by $20 \%$, with the reductions of $14.49 \%$ and $16.03 \%$, respectively.

\section{References}

Abbaspour K C, Johnson C A, Genuchten M T V, 2004. Estimating uncertain flow and transport parameters using a sequential uncertainty fitting procedure. Vadose Zone Journal, 3(4): 1340-1352.

Akhavan S, Abedi-Koupai J, Mousavi S F et al., 2010. Application of SWAT model to investigate nitrate leaching in Hamadan-Bahar Watershed, Iran. Agriculture Ecosystems \& Environment, 139(4): 675-688.

Alcon F, Miguel M D D, Burton M, 2011. Duration analysis of adoption of drip irrigation technology in southeastern Spain. Technological Forecasting \& Social Change, 78(6): 991-1001.

Al-Mukhtar M, Dunger V, Merkel B, 2014. Assessing the impacts of climate change on hydrology of the upper reach of the Spree River: Germany. Water Resources Management, 28(10): 2731-2749.

Ba W L, Du P F, Liu T et al., 2018. Simulating hydrological responses to climate change using dynamic and statistical downscaling methods: A case study in the Kaidu River Basin, Xinjiang, China. Journal of Arid Land, 10(6): 905-920.

Basher M A, Liu T, Kabir M A et al., 2010. Climate change impact on the hydrological extremes in the Kaidu River Basin, China. Journal of Flood Engineering, 1(2): 93-108.

Bouraoui F, Grizzetti B, 2014. Modelling mitigation options to reduce diffuse nitrogen water pollution from agriculture. Science of the Total Environment, 468: 1267-1277.

Chamchati H, Bahir M, 2011. Contributions of climate change on water resources in semi-arid areas: Example of the Essaouira Basin (Morocco). Geographia Technica, 1(1): 1-8.

Chen C C, Chen Y N, Yang Y H et al., 2010. Hydrology and water resources variation and its response to regional climate change in Xinjiang. Journal of Geographical Sciences, 20(4): 599-612.

Chen J J, 2002. Analysis of water environment in the Xinjiang arid region. Arid Environmental Monitoring, 16(4): 223-224. (in Chinese)

Chen Y N, Yang Q, Luo Y et al., 2012. Ponder on the issues of water resources in the arid region of northwest China. Arid Land Geography, 35(1): 1-9. (in Chinese)

Dechmi F, Skhiri A, 2013. Evaluation of best management practices under intensive irrigation using SWAT model. Agricultural Water Management, 123: 55-64.

Dibike Y B, Coulibaly P, 2005. Hydrologic impact of climate change in the Saguenay watershed: Comparison of downscaling methods and hydrologic models. Journal of Hydrology, 307(1-4): 145-163. 
Griensven A V, Ndomba P, Yalew S et al., 2012. Critical review of the application of SWAT in the upper Nile Basin countries. Hydrology \& Earth System Sciences Discussions, 9(3): 3761-3788.

Guo M, Zhou X, Li J et al., 2015. Assessment of the salinization processes in the largest inland freshwater lake of China. Stochastic Environmental Research \& Risk Assessment, 29(7): 1823-1833.

Gupta H V, Sorooshian S, Yapo P O, 1999. Status of automatic calibration for hydrologic models: Comparison with multilevel expert calibration. Journal of Hydrologic Engineering, 4(2): 135-143.

Kaini P, Nicklow J W, 2012. Optimizing structural best management practices using SWAT and genetic algorithm to improve water quality goals. Water Resources Management, 26(7): 1827-1845.

Lei X, Lu J, Liu Z et al., 2015. Concentration and distribution of antibiotics in water-sediment system of Bosten Lake, Xinjiang. Environmental Science \& Pollution Research International, 22(3): 1670-1678.

Liu T, Willems P, Pan X L et al., 2011. Climate change impact on water resource extremes in a headwater region of the Tarim Basin in China. Hydrology and Earth System Sciences, 15(11): 3511-3527.

Liu Y, Mu S, Bao A et al., 2015. Effects of salinity and (an)ions on arsenic behavior in sediment of Bosten Lake, Northwest China. Environmental Earth Sciences, 73(8): 4707-4716.

Mihon D, Bacu V, Rodila D et al., 2013. Grid based hydrologic model calibration and execution. In: Dumitrache L (eds.). Advances in Intelligent Control Systems and Computer Science. Berlin Heidelberg: Springer, 279-293

Moriasi D N, Arnold J G, Liew M W V et al., 2007. Model evaluation guidelines for systematic quantification of accuracy in watershed simulations. Transactions of the ASABE, 50(3): 885-900.

Moriasi D N, Gowda P H, Arnold J G et al., 2013. Modeling the impact of nitrogen fertilizer application and tile drain configuration on nitrate leaching using SWAT. Agricultural Water Management, 130: 36-43.

Mostofa K M G, Li W, Wu F et al., 2017. Environmental characteristics and changes of sediment pore water dissolved organic matter in four Chinese lakes. Environmental Science \& Pollution Research, 25(5): 1-22.

Neitsch S L, Arnold J G, Kiniry J R et al., 2011. Soil and water assessment tool theoretical documentation version 2009, Texas water resources institute, technical report No. 406. Texas: Texas A\&M University System College Station.

Pongpetch N, Suwanwaree P, Yossapol C et al., 2015. Using SWAT to assess the critical areas and nonpoint source pollution reduction best management practices in Lam Takong River Basin, Thailand. Environmentasia, 8(1): 41-52.

Rusuli Y, Li L, Ahmad S et al., 2015. Dynamics model to simulate water and salt balance of Bosten Lake in Xinjiang, China. Environmental Earth Sciences, 74(3): 2499-2510.

Shen B B, Wu J L, Zhao Z H, 2017. Organochlorine pesticides and polycyclic aromatic hydrocarbons in water and sediment of the Bosten Lake, Northwest China. Journal of Arid Land, 9(2): 287-298.

Wang G, 1999. The utilization of water resource and its influence on eco-environment in the northwest arid area of china. Journal of Natural Resources, 43(2): 121-131. (in Chinese)

Wang S X, Wu B, Yang P N et al., 2011. Determination of the ecological groundwater depth considering ecological integrity over oasis irrigation areas in the Yanqi Basin. Resources Science, 33(3): 422-430. (in Chinese)

Wang S X, Wu B, Yang P N, 2014. Assessing the changes in land use and ecosystem services in an oasis agricultural region of Yanqi Basin, Northwest China. Environmental Monitoring \& Assessment, 186(12): 8343-8357. (in Chinese)

Wang X J, Yu Z T, Wang J P et al., 2018. Carbon Cycle in the Changing Arid Land of China. Singapore: Springer.

Xiao J, Jin Z, Jin W et al., 2015. Major ion chemistry, weathering process and water quality of natural waters in the Bosten Lake catchment in an extreme arid region, NW China. Environmental Earth Sciences, 73(7): 3697-3708.

Xie X, Cui Y, 2011. Development and test of SWAT for modeling hydrological processes in irrigation districts with paddy rice. Journal of Hydrology, 396(1): 61-71.

Yu Y, Pi Y Y, Yu X et al., 2019. Climate change, water resources and sustainable development in the arid and semi-arid lands of Central Asia in the past 30 years. Journal of Arid Land, 11(1): 1-14.

Zhang X Y, Zhang M H, 2011. Modeling effectiveness of agricultural BMPs to reduce sediment load and organophosphate pesticides in surface runoff. Science of the Total Environment, 409(10): 1949-1958.

Zuo Q T, Zhou K F, Xia J et al., 2007. A quantified study method and its application to sustainable management of water resources in arid basins. Science in China (Series D), 50(1): 9-15. 